\title{
TINGKAT KESUBURAN TANAH PADA AREAL EKS PENEBANGAN HUTAN DI AREAL HPH PT. KSK NANGA PINOH KAB. MELAWI
}

(The level of soil fertility in logged forest area in KSK nanga pinoh company at melawi district)

\section{Siti Latifah, Ratna Herawatiningsih}

Fakultas Kehutanan Universitas Tanjungpura Jalan Imam Bonjol Pontianak 78124

Email: sitilatifah@fahutan.untan.ac.id, rherawatiningsih@yahoo.co.id

\begin{abstract}
Abstrak
Forest harvesting is a logging activity, distribution of trunks, skidding, loading and transportation. This activity involves a lot of heavy equipment that results in soil compaction and reduced vegetation cover. This condition causes changes in soil fertility conditions. This study aims to determine changes in soil fertility that occur due to forest exploitation activities. Namely by observing the physical and chemical properties of the soil in the area of the former skid trail, ex-TPn, former TPk, former logging areas. The research method used for data retrieval is the survey method with porposive sampling, while the data obtained is analyzed using descriptive analysis. Based on the results of the analysis of the physical and chemical properties of the soil, it shows that the former TPN area is the area with the lowest soil fertility value. Former logging areas have the best quality of soil fertility compared to other areas; such as former skid trails, former TPk and former Tpn areas even though they are still included in the low fertility classification, with organic matter in the former logged area of $2.24 \%$. The organic matter content is only $0.8 \%$ with clay texture.
\end{abstract}

Keyword: harvesting, forest, forest land, soil fertility

\section{PENDAHULUAN}

Secara umum kegiatan pemanenan hutan terdiri dari tahapan perencanaan pembukaan wilayah hutan (PWH) seperti perencanaan jalan sarad dan penentuan lokasi TPn, penebangan, penyaradan, dan pengangkutan. Perencanaan pemanenan memiliki peranan yang sangat penting dalam pemilihan sistem pemanenan, alat yang digunakan, jumlah tenaga kerja, biaya,luas setting pemanenan, minimalisasi dampak sehingga tercapai proses pemanenan hutan yang optimal. Pemanenan hutan yang dilakukan tanpa perencanaan yang tepat dapat menyebabkan keseimbangan hutan terganggu.

Menurut Budiaman (2003), komponen utama pemanenan kayu pada umumnya terdiri dari 5 kegiatan, yaitu penebangan pohon, pembagian batang, penyaradan, pemuatan dan pengangkutan. Selain itu pada tahapan tertentu, misalnya penebangan terdapat kegiatan tambahan yaitu pemotongan ujung dan pangkal kayu serta pemotongan cabang. Dalam melaksanakan kegiatan penebangan PT. Sari Bumi Kusuma telah menerapkan metode Reduced Impact Logging (RIL) dalam skala operasionalnya, dengan tujuan untuk mengurangi dampak negatif terhadap kerusakan tanah dan tegakan tinggal akibat penebangan dan penyaradan. RIL sering juga disebut RITH (Reduced Impact Timber Harvesting) adalah suatu teknik pemanenan kayu yang direncanakan secara intensif, dalam 6 pelaksanaan operasinya menggunakan 
teknik pelaksanaan dan peralatan yang tepat serta diawasi secara intensif untuk meminimalkan kerusakan terhadap tegakan tinggal dan tanah (Elias 2002).

Pemanfaatan hutan dalam bentuk penebangan yang tidak memperhatikan aspek kelestarian dapat menyebabkan berbagai dampak negatif terhadap tanah,air, flora dan fauna, perubahan iklim, dan unsur hara. Dampak negatif terhadap tanah antara lain rusaknya sifat fisik dan kimia tanah, terganggunya siklus hidroorologi, menstimulasi erosi, dan meningkatkan sedimen tersuspensi dalam tubuh air. Akibatnya tanah menjadi miskin hara dan hanya beberapa jenis tumbuhan tertentu yang dapat bertahan hidup di atas tanah tersebut (Pratiwi dan Budi M, 2002)

Hasil penelitian yang dilakukan oleh Soedomo (1993), menunjukkan adanya penurunan porositas tanah sebesar 5,9\% akibat dari kegiatan penebangan kayu, $12,4 \%$ akibat kegiatan pembuatan jalan dan $14,7 \%$ akibat kegiatan penimbunan kayu. Bobot isi tanah mengalami peningkatan sebesar 27,72 \% karena kegiatan penebangan kayu, 25, $0 \%$ karena pembuatan jalan dan 21,83\% ditempat penimbunan kayu. Pada umumnya perubahan penggunaan lahan (landuse), perbedaan polatanam dan konversi hutan menjadi lahan pertanian dapat mempengaruhi kadar bahan organik tanah (Anas, I., D.A, Santosa., R. Widyastuti, 1995).

Demikian pula halnya dalam kegiatan pemanenan hutan dapat menurunkan bahan organik, khususnya $\mathrm{C}$ dan $\mathrm{N}$ secara drastis akibat perubahan suhu, lengas tanah dan aerasi (Matson et al 1987 di acu dalam Buchari 2002). Hasil penelitian yang dilakukan oleh Pamoengkas (1997) terhadap sifat kimia lain seperti kapasitas tukar kation (KTK) dan kation yang dapat ditukar seperti kalium $(\mathrm{K})$, natrium $(\mathrm{Na})$, kalsium (Ca) dan magnesium ( $\mathrm{Mg}$ ) pada hutan yang belum terganggu dengan rumpang (gap) kecil yang berukuran 60 $\mathrm{m} 2$, rumpang (gap) besar berukuran 120 $\mathrm{m} 2$ dan 2 jalan sarad yang masing-masing telah mendapat perlakuan 4 kali dan 15 kali di lalui traktor. Diperoleh adanya penurunan nilai KTK pada hutan dengan rumpang (gap) kecil yang relatif sama jika dibandingkan dengan dengan hutan primer, namun untuk hutan dengan rumpang (gap) besar terjadi penurunan nilai KTK yang reatif lebih tinggi. Sedangkan untuk nilai kation yang dapat ditukar seperti kalium $(\mathrm{K})$, natrium $(\mathrm{Na})$, kalsium (Ca) dan magnesium ( $\mathrm{Mg}$ ) pada setiap lokasi adalah relatif sama. Berdasarkan hasil penelitian yang telah dilakukan oleh Ajeng (2006), menunjukkan bahwa nilai bobot isi tanah pada seluruh plot penelitian berada pada kisaran 1,02-1,39 $\mathrm{g} / \mathrm{cm} 3$ atau termasuk dalam kategori sedang, yaitu 1-1,5 g/cm3 (Poerwowidodo, 2000) dan tidak berbeda nyata antar plot. Nilai bobot isi terendah adalah pada hutan primer dan peningkatan terbesar terjadi pada hutan bekas tebangan 1 bulan sebesar 0,25\%. Dengan meningkatnya BI menyebabkan porositas menurun sehingga menghambat pergerakan udara dan air, akibatnya penetrasi dan perkembangan akar pun terhambat. Penurunan terbesar adalah pada hutan bekas tebangan 1 bulan sebesar 9,15\% dan terus meningkat sampai pada hutan tanaman umur 7 tahun menjadi $61,70 \%$. Secara kuantitatif BI mempunyai 
kecenderungan meningkat pada lapisan yang lebih dalam, sedangkan porositas semakin menurun pada lapisan yang lebih dalam.

Proses pemanenan hutan meliputi penebangan, penyaradan, pengangkutan, dan pngumpulan kayu menyebabkan areal penebangan tidak hanya mengalami kerusakan karena proses penebangan saja, tetapi juga mengalami kerusakan akibat proses penyaradan dan pengangkutan di jalan sarad, pembersihan lahan untuk pengumpulan kayu. Setiap areal permukaan tanah yang ada di lokasi penebangan mengalami perlakuan yang berbeda- beda. Dengan demikian kerusakan yang terjadi pada setiap areal juga akan berbeda-beda.

Penelitian ini bertujuan untuk mengetahui tingkat kesuburan tanah yang terjadi akibat adanya kegiatan eksploitasi hutan. Yaitu dengan mengamati tingkat kesuburan tanah pada areal bekas jalan sarad, bekas TPn, bekas TPk, areal bekas penebangan, serta areal yang belum ada kegiatan penebangan (hutan alam).

\section{METODE PENELITIAN}

Penelitian ini dilaksanakan di Areal HPH PT. Kalimantan Setya Kencana Nanga Pinoh Kabupaten Melawi selama 12 hari di lapangan untuk pengambilan sampel tanah serta analisis sampel tanah di Laboratorium Tanah Fakultan Pertanian UNTAN Pontianak selama 21 hari.

Pengumpulan data primer dilakukan melalui kerja lapangan yaitu mengambil sampel tanah terganggu dan tak tergangga pada areal bekas jalan sarad, bekas TPn, bekas TPk, bekas areal penebangan, dan lahan hutan alam yang ada di Areal HPH PT. Kalimantan Setya Kencana Nanga Pinoh Kabupaten Melawi. Sampel tanah ini selanjutnya dianalisis sifat fisiknya ( tekstur tanah, struktur tanah, porositas tanah, kerapatan zarah, dan permeabilitas tanah) dan kimia tanah (C, N, P, K, KTK, $\mathrm{pH})$ di laboratorium tanah Fak. Pertanian UNTAN.

\section{HASIL DAN PEMBAHASAN}

Berdasarkan hasil pengamatan dilapangan dan hasil analisis sampel tanah yang diambil dari areal HPH PT. KSK diperoleh rerata hasil sebagai berikut : 
JURNAL TENGKAWANG (2018)

Vol. 8 (1) : 50 - 58

Tabel 1. Hasil Analisa Sifat Fisik Dan Kimia Tanah di Areal HPH. PT. KSK Melawi

\begin{tabular}{lrrrcccccc}
\hline & Pasir & Debu & Liat & pH & C-Org & N-total & $\mathbf{P}_{2} \mathbf{O}_{3}$ & K & KTK \\
\hline hutan (1) & 45,68 & 22,6 & 31,72 & 4,22 & 1,88 & 0,2 & 3,72 & 0,46 & 10,28 \\
hutan (2) & 54,13 & 18,59 & 27,28 & 4,46 & 2,16 & 0,22 & 6,31 & 0,07 & 11,77 \\
tebangan 1 & 57,56 & 17,78 & 24,67 & 4,4 & 1,36 & 0,15 & 5,31 & 0,09 & 9,99 \\
tebangan 2 & 52,61 & 20,57 & 26,87 & 4,62 & 1,22 & 0,13 & 0,91 & 0,07 & 9,26 \\
TPn 1 & 36,48 & 24,59 & 38,94 & 4,81 & 0,17 & 0,03 & 4,81 & 0,33 & 6,13 \\
TPn 2 & 9,88 & 44,82 & 45,3 & 5,04 & 0,16 & 0,03 & 5,74 & 0,66 & 6,16 \\
Tpk 1 & 27,92 & 34,84 & 37,23 & 5,06 & 1,51 & 0,16 & 3,64 & 0,05 & 10,06 \\
TPk 2 & 30,94 & 27,8 & 41,26 & 4,9 & 1 & 0,11 & 1,51 & 0,05 & 8,49 \\
J1. Sarad 1 & 11,92 & 42,84 & 45,23 & 4,34 & 0,55 & 0,06 & 0,3 & 0,25 & 6,92 \\
J1 Sarad 2 & 16,12 & 38,42 & 45,46 & 4,71 & 0,53 & 0,06 & 0,3 & 0,13 & 6,96 \\
\hline
\end{tabular}

Berdasarkan data tabel 1 terlihat bahwa secara umum sifat fisik dan kimia tanah yang paling baik adalah areal hutan alam, selain itu kondisi areal bekas tebangan juga mempunyai kondisi yang relatif baik hampir sama dengan kondisi hutan alam.

Berdasarkan data analisis tanah tabel 1 nilai rerata hasil analisis tanah untuk setiap areal sampel ditampilkan dalam grafik analisis tekstur tanah (gambar 1) dan grafik nilai $\mathrm{pH}$, KTK dan $\mathrm{C} / \mathrm{N}$ rasio tanah (gambar 2). Kandungan hara makro yang terkandung pada setiap areal lokasi sampel nilai reratanya ditampilkan dalam grafik rerata kandungan bahan Corganik dan P (gambar 3).

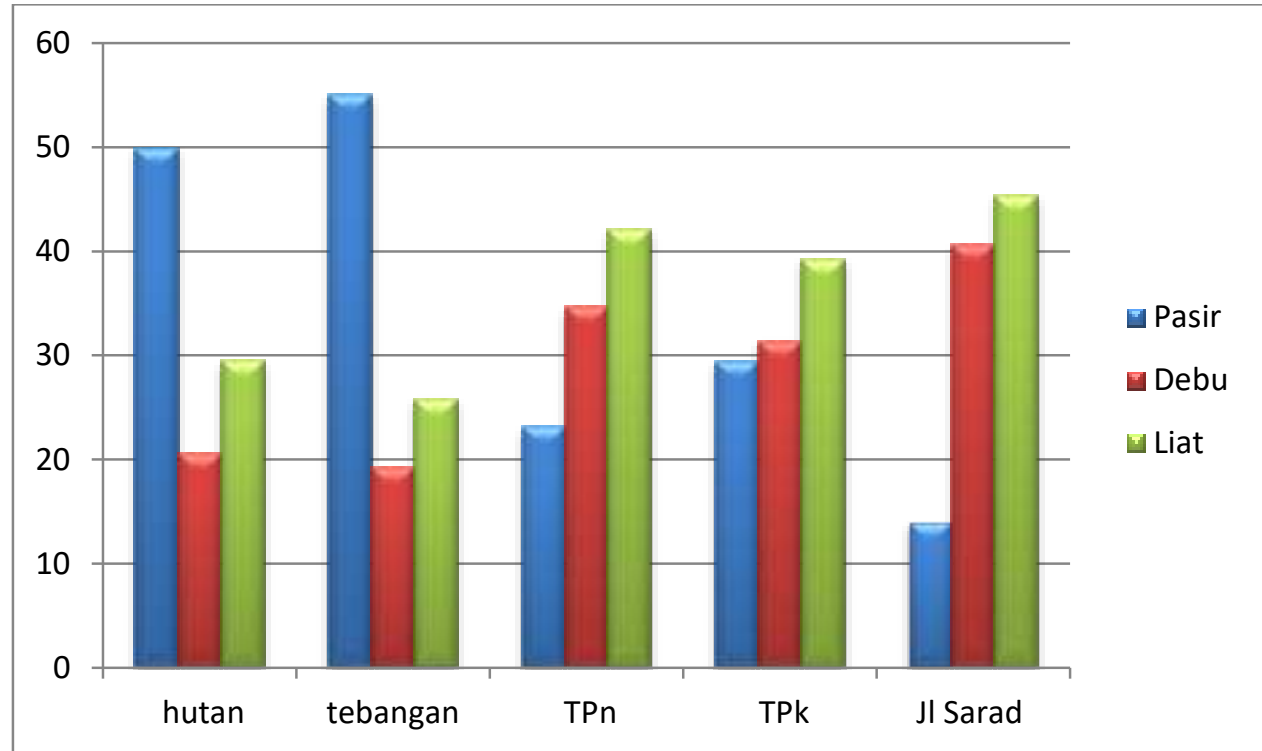

Gambar 1. Rerata tekstur tanah pada Areal Penelitian

Berdasarkan grafik nilai rerata tekstur tanah hutan dan areal bekas tebangan klasifikasi tekstur tanah termasuk pada klasifikasi sedang, sedangkan jalan sarad klasifikasinya termasuk kedalam klasifikasi tekstur halus. 
JURNAL TENGKAWANG (2018)

Vol. 8 (1) : 50 - 58

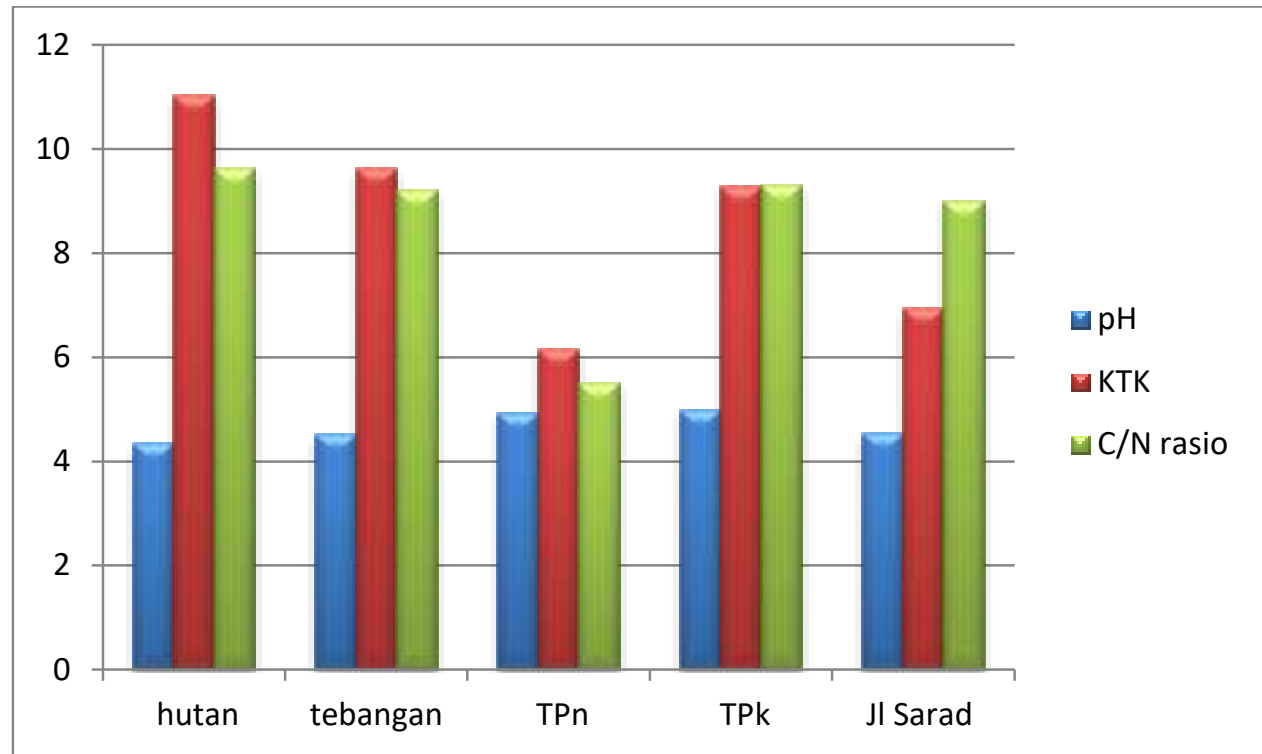

Gambar 2. Rerata nilai pH, KTK dan Rasio C/N pada Areal Penelitian

Berdasarkan hasil analisa, nilai Organik (gambar 3), sedangkan rerata $\mathrm{pH}$, KTK, dan Rasio C/N yang kandungan $\mathrm{P}$ dan $\mathrm{K}$ (gambar 4) TPn terbaik adalah pada areal hutan. mempunyai nilai yang tertinggi.

Demikian juga dengan kandungan $\mathrm{C}$ -

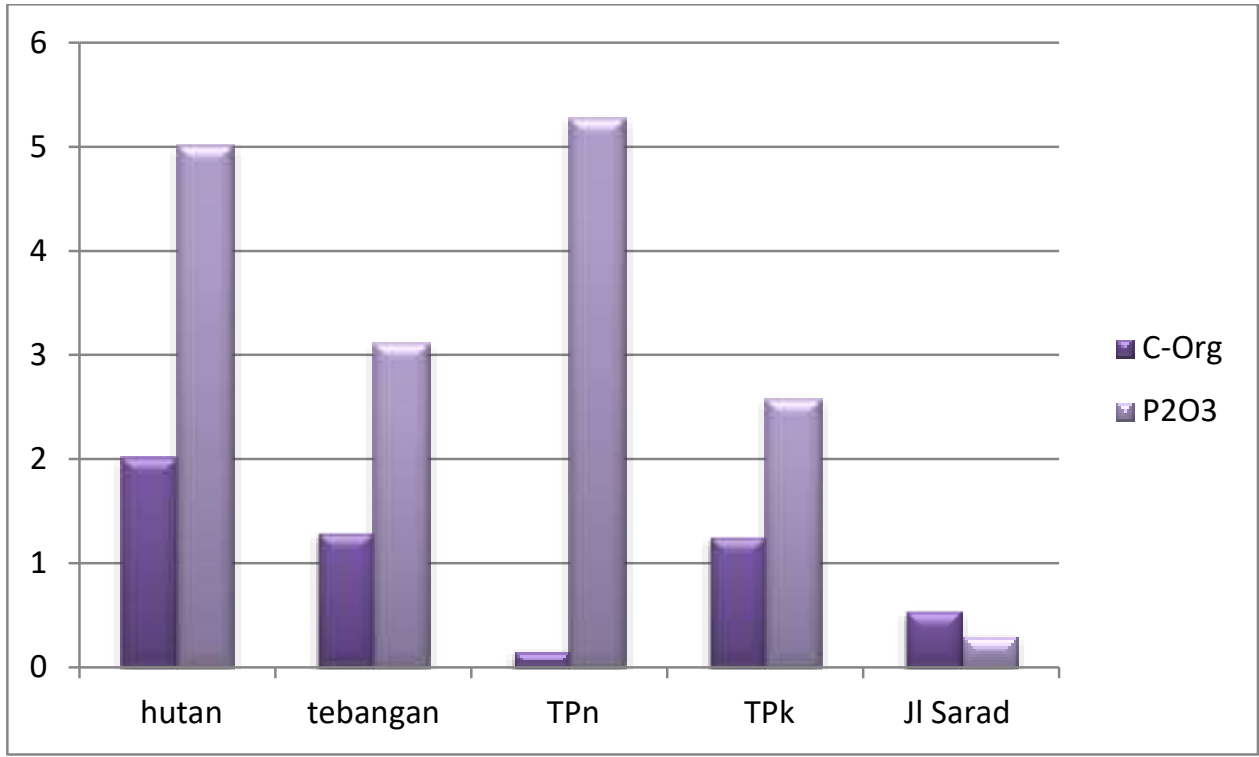

Gambar 3. Grafik rerata kandungan C-organik dan P pada areal penelitian

Nilai rerata kandungan $\mathrm{N}$ total pada areal hutan juga merupakan nilai rerata tertinggi, namun untuk kandungan $\mathrm{K}$ dan $\mathrm{P}$ areal TPn mempunyai nilai rerata tertinggi (gambar 3 dan 4). 


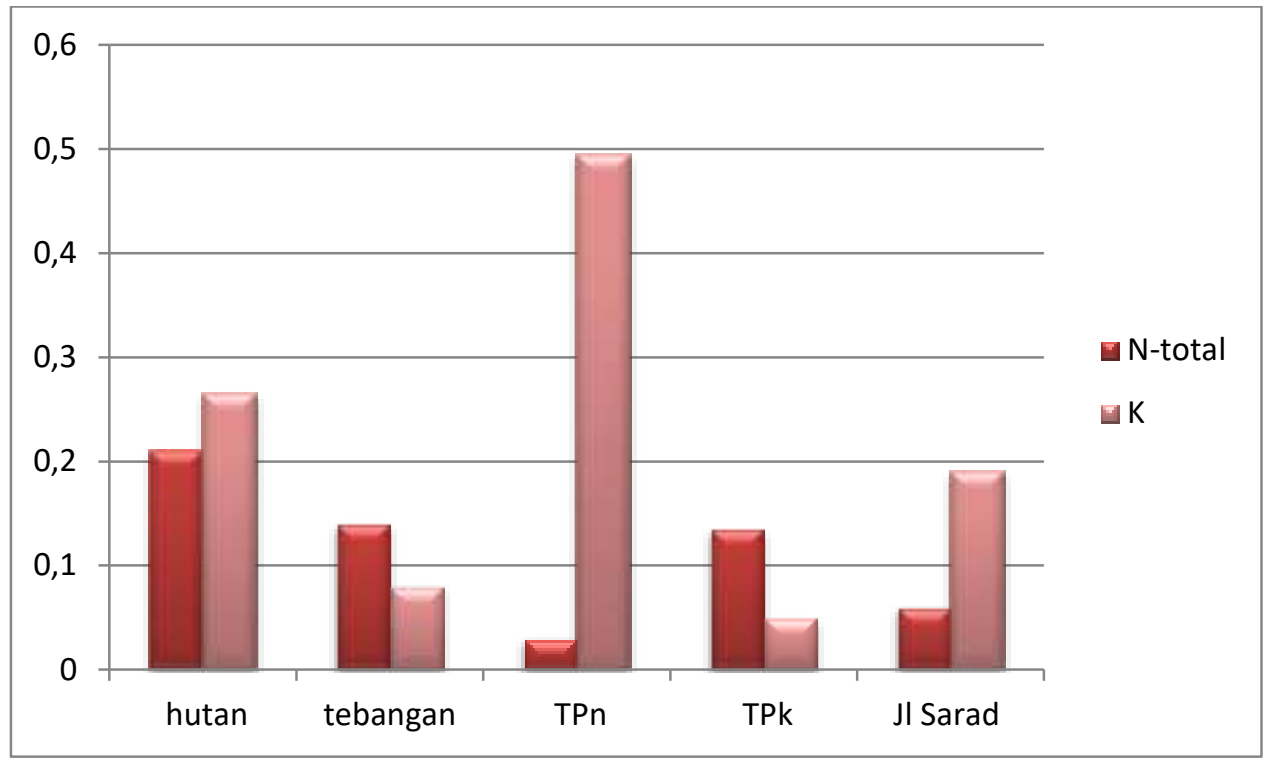

Gambar 4. Rerata kandungan N-total dan K pada setiap areal penelitian

Kondisi sifat fisik tanah ini sangat dipengaruhi oleh kondisi penutupan lahannya. Berdasarkan penutupan lahan yang ada kondisi lahan hutan merupakan lahan yang masih tertutup dengan vegetasi yang cukup rapat. Pada lahan bekas tebangan dan bekas jalan sarad merupakan lahan yang masih tertutup juga oleh vegetsi meskipun dengan kerapatan yang berbeda.

Kondisi lahan bekas TPn merupakan kondisi yang paling buruk kondisi sifat fisik tanahnya. Hal ini disebabkan kondisi lahan yang terbuka tanpa penutupan vegetasi. Berbeda dengan areal bekas TPk meskipun relative terbuka, namun masih terdapat serasah sisa kayu serta kanan dan serasah daun serta sebagian telah ditanami kembali dengan bibit tanaman hutan (gambar 8), sehingga kandungan bahan organiknya masih lebih tinggi bila dibandingkan areal TPn yang mempunyai kandungan bahan organik paling rendah hanya berkisar $0,3 \%$ (gambar 3).

Hasil analisis tanah bila dibandingkan dengan standar kesuburan tanah maka kondisi tanah yang ada di areal penelitian masih termasuk dalam klasifikasi kesuburan rendah, sedangkan untuk areal jalan sarad dan TPn termasuk kedalam klasifikasi sangat rendah.

\section{PEMBAHASAN}

Berdasarkan hasil analisa fisika dan kimia tanah terlihat bahwa kondisi tanah hutan yang ada di areal penelitian termasuk pada klasifikasi yang rendah. Tanah hutan merupakan tanah yang tingkat kesuburannya rendah tetapi tanah hutan mempunyai cadangan bahan organik yang tinggi. Berdasarkan hasil penelitian Widyanto, dkk (2014) ternyata kandungan nutrisi tanah yang ada di hutan alam di areal PT. Sari Bumi Kusuma (SBK) blok Sei Seruyan termasuk kedalam katagori rendah (kandungan $\mathrm{Ca}, \mathrm{K}, \mathrm{Mg}$ ). Namun 
demikian hutan mempunyai persediaan bahan organik berupa serasah yang cukup tinggi berkisar antara 9,05 11,75 ton/ha/tahun.

Kikuchi (1996), menyebutkan bahwa akumulasi seresah dan ketebalan BO berhubungan dengan intensitas cahaya matahari dan kelembaban udara yang berada pada lokasi tersebut. Areal yang mempunyai intensitas cahaya tinggi dan kelembaban rendah maka kandungan seresah dan ketebalan BO akan lebih kecil dibandingkan areal yang mempunyai intensitas cahaya rendah dan kelembaban tanah tinggi. Selanjutnya (Buckman dan Brady, 1982) menyatakan Keberadaan BO ini berperan dalam memengaruhi sifat fisika dan kimia tanah, pengaruhnya relatif sangat besar dibanding dengan jumlahnya yang sedikit dalam tanah sehingga keberadaan vegetasi penyusun tegakan menjadi faktor kunci sebagai penyumbang $\mathrm{BO}$ untuk peningkatan produktivitas BO dan kesuburan tanah.

Pada lahan hutan meskipun mempunyai cadangan bahan organik yang tinggi dalam bentuk serasah, namun ketersediaan haranya rendah. Hal ini disebabkan lambatnya dekomposisi serasah hutan seperti yang dikemukakan oleh Widyanto dkk (2014) yang menyatakan bahwa kandungan $\mathrm{Ca}, \mathrm{K}, \mathrm{Mg}, \mathrm{N}$, dan $\mathrm{P}$ mempunyai kadar yang termasuk pada klasifikasi rendah tetapi untuk kandungan C-organik kandungannya termasuk pada klasifikasi tinggi lebih besar dari $4 \%$. Hutan yang berada pada areal penelitian kandungan Corganiknya termasuk pada klasifikasi sedang 2,02 \% dan ini merupakan kandungan $\mathrm{C}$ tertinggi bila dibandingkan dengan areal bekas tebangan, TPk, TPn, dan jalan sarad. Namun dengan pengembangan struktur yang mantap terbentuklah salah satu fungsi yang menjadi andalan utamanya yaitu "siklus hara tertutup" (closed nutrient cycling) dan keterkaitan komponen tersebut, sehingga mampu mengatasi berbagai kendala/keunikan tipe hutan ini (Withmore, 1975).

Selain kandungan C-organik yang tinggi hutan juga memiliki nilai KTK yang tertinggi yaitu 11,025 cmol/100. Kandungan C-organik yang tinggi menyebabkan aktifitas mikroorganismenya juga tinggi. Mikroorganisme bertugas sebagai dekomposer serasah, serasah yang terdekomposisi merupakan sumber hara bagi tanaman. Dengan demikian tanah hutan mempunyai cadangan hara yang cukup banya dalam bentuk sersah. Namun demikian tanah hutan merupakan tanah yang rentan akan penurunan kualitas pada saat hutan tersebut terbuka karena penebangan maupun kegiatan lain. Keterbukaan hutan dapat menyebabkan tanah lapisan atas terbuka, sehingga tanah mudah tererosi dan lapisan serasah juga ikut tererosi air permukaan. Dengan demikian lapisan yang subur akan hilang bersamaan dengan aliran air permukaan. Kenyataan-kenyataan tersebut menunjukkan bahwa hutan hujan tropis merupakan ekosistem yang rapuh (fragile ecosystem), karena setiap komponen tidak bisa berdiri sendiri (Marsono, 1991). 
TPn merupakan areal yang paling rendah kesuburannya, salah satu penyebab rendahnya kesuburan tanah di aresl TPn ini adalah lahan TPn merupakan lahan yang sangat terbuka. Kondisi ini menyebabkan tidak ada serasah di permukaan tanah(gambar 7), karena merupakan tempat penimbunan kayu areal ini juga merupakan areal yang mengalami pemadatan akibat beban kayu yang ditimbun di atasnya. Berdasarkan hasil analisa sifa fisik tanah (lampiran 1) tanah pada areal ini mempunyai tekstur liat dengan nilai permiabilitas yang termasuk dalam klasifikasi sangat rendah. Pada tanah bertekstur liat dengan permiabilitas sangat lambat akan bepengaruh pada nilai KTK, KTK ini juga akan berpengaruh pada pertukaran unsur hara pada tanah.

Jalan sarad meskipun merupakan areal terbuka namun masih berada di areal hutan, sehingga serasah masih ada di areal ini demikian juga dengan areal bekas tebangan. Areal bekas tebangan kondisinya lebih baik dari jalan sarad, hal ini disebabkan areal bekas tebangan telah mengalami suksesi, sehingga tanamannya .banyak bila dibandingkan dengan jalan sarad. Sehingga meskipun jalan sarad, bekas tebangan dan TPk termasuk pada klasifikasi kesuburan tanah rendah namun kandungan bahan organik tanah pada areal bekas tebangan lebih tinggi bila dibandingkan dengan areal TPk. Areal TPk mempunyai kandungan bahan organik lebih tinggi bila dibandingkan jalan sarad karena areal ini telah ditumbuhi tanaman bawah. Tumbuhan bawah juga merupakan sumber bio massa yang juga merupakan sumber bahan organik. Dengan demikian kondisi kesuburan TPk menjadi lebih baik bila dibandingkan dengan jalan sarad.

Areal bekas tebangan juga memiliki tingkat kesuburan yang lebih baik bila dibandingkan dengan TPk maupun jalan sarad. Aral bekas tebangan yang telah berumur 1 tahun telah mengalami suksesi. Suksesi ini dapat terjadi dengan cepat karena penebangan dilaksanankan dengan cara tebang pilih, sehingga masih banyak tanaman yang tersisa dan areal tidak terbuka. Peningkatan vegetasi berarti penambahan sumber bahan oganik yang mempunyai kemampuan untuk memperbaiki sifat fisika dan kimia tanah.

\section{KESIMPULAN DAN SARAN}

Berdasarkan hasil penelitian dan analisis sifat fisik tanah dan bahan organik dapat disimpulkan bahwa, dari seluruh areal penebangan maka areal yang kondisinya paling jelek adalah areal TPn, sedangkan areal bekas jalan sarad dan bekas TPk memepunyai kondisi yang masih relative lebih baik. Hal ini disebabakan di sekitar TPk dan bekas jalan sarad masih ada vegetasinya, sehingga masih ada sumber bahan organik. Areal bekas tebangan merupakan areal yang paling baik kondisinya. Hal ini disebabkan penebangan yang dilakukan menggunakan system silvikultur tebang pilih.

Berdasarkan hasil analis dan pembahasan terlihat bahwa untuk menjaga agar kondisi hutan tetap terjaga kesuburan tanah hutan maka sebaiknya 
penebangan dilakukan dengan menggunakan system silvikultur tebang pilih. Kondisi hutan akan semakin terjaga kesuburan tanahnya bila setelah masa penanaman maka areal bekas tebangan, jalan sarad, TPk dan TPn segera ditanami kembali setelah proses penebangan selesai. Dengan demikian suksesi hutan akan berjalan dengan cepat.

\section{DAFTAR PUSTAKA}

Elias. 1980. Pembukaan Wilayah Hutan. Fakultas Kehutanan IPB. Bogor.

Hamzah, Z. 1983. Ilmu Tanah Hutan. Proyek Peningkatan Pengembangan Perguruan Tinggi. Institut Pertanian Bogor. Bogor.

Matangaran, J.R., R.S. Suprapto, D. Tinambunan dan S. Manan. 1995. Pengaruh Intensitas Penyaradan Kayu oleh Traktor Berban Ulat Terhadap Pemadatan tanah dan pertumbuhan kecambah. Jurnal penelitian Hasil hutan. Vol. VIII No. 1. hal 29 - 34.

Poerwowidodo. 1992. Metode Selidik tanah. Usaha Offset Printing. Surabaya.
Tinambunan. 1987. Pentingnya Peningkatan Usaha Pengendalian Gangguan Lingkungan Dalam Pengusahaan Hutan. Duta Rimba XIII (83 - 84) : 11-15.

Widiyatno, Soekotjo, Hatma Suryatmojo, Haryono Supriyo, Susilo Purnomo dan Jatmoko, 2013, Dampak Penrapan Sistem Silvikultur Tebang Pilh Tanam Jalur Terhadap Kelestarian Kesuburan Tanah Dalam Menunjang Kelestarian Pengelolaan Hutan Alam. Jurnal. MANUSIA DAN LINGKUNGAN, Vol. 21, No.1, Maret. 2014: 50-59. UGM yogyakarta

Wronski, E. B. 1984. Impact of Tractor Thinning Operation on Soil and Tree Roots in a Karri Forest, Weatern Australia. Aust. For. Res., 14 : 319 -332.

Yulnafatmawita, Adrinal, dan Arief Fauzan Hakim, 2011. Pencucian Bahan Organik Tanah Pada Tiga Penggunaan Lahan Daerah Hutan Hujan Tropis Super Basas Pinang-Pinang Gunung Gadut Padang, Journal Solum Vol VIII No.1 Januari 2011: 34-42. Universitas Andalas Padang 